\title{
Bladder cancer cell-derived exosomes inhibit tumor cell apoptosis and induce cell proliferation in vitro
}

\author{
LIN YANG $^{1}$, XIAO-HOU WU ${ }^{1}$, DAN WANG $^{1}$, CHUN-LI LUO ${ }^{2}$ and LI-XUE CHEN ${ }^{3}$ \\ ${ }^{1}$ Department of Urology, The First Affiliated Hospital of Chongqing Medical University; \\ ${ }^{2}$ Department of Laboratory Diagnostics, College of Laboratory Medicine, Chongqing Medical \\ University; ${ }^{3}$ Experimental Research Center, The First Affiliated Hospital of Chongqing Medical \\ University, Chongqing Key Laboratory of Neurology, Yuzhong, Chongqing 400016, P.R. China
}

Received January 14, 2013; Accepted August 9, 2013

DOI: $10.3892 / \mathrm{mmr} .2013 .1634$

\begin{abstract}
Exosomes are small membrane vesicles released by a variety of mammalian cells into the extracellular space and are involved in cell-to-cell signaling. This study aimed to investigate the effects of bladder cancer cell-derived exosomes on the regulation of tumor cell viability and apoptosis, as well as the underlying molecular events. Exosomes were purified from the supernatants of human bladder cancer T24 cell cultures. Transmission electron microscopy was used to confirm their morphology and western blot analyses determined the protein content of cells. Subsequently, bladder cancer cell lines were treated with different concentrations of exosomes. Tumor cell viability was shown to be reduced, as detected by the Cell Counting Kit- 8 assay. Annexin V/flow cytometric assays showed that exosomes inhibited apoptosis of bladder cancer cell lines in a dose- and time-dependent manner. Exosomes were demonstrated to upregulate the expression of Bcl-2 and Cyclin D1 proteins, but reduce the levels of Bax and caspase- 3 proteins in these cells. Moreover, exosomes dose-dependently increased the expression of phosphorylated Akt and extracellular signal-regulated protein kinase (ERK). In conclusion, this study demonstrated that bladder cancer cell-derived exosomes inhibited tumor cell apoptosis, which was associated with the activation of Akt and ERK pathway genes, suggesting that tumor-derived exosomes are involved in bladder cancer progression. Inhibition of exosome formation and release may therefore be a novel strategy in future treatment of bladder cancer.
\end{abstract}

Correspondence to: Professor Xiao-Hou Wu, Department of Urology, The First Affiliated Hospital of Chongqing Medical University, 1 Youyi Road, Yuzhong, Chongqing 400016, P.R. China E-mail: screnyang@163.com

Key words: exosomes, bladder cancer, proliferation, apoptosis, mitogen-activated protein kinase/extracellular signal-regulated kinase and phoshoinositide-3-kinase/Akt signaling pathways

\section{Introduction}

Bladder cancer is a significant health problem, accounting for $\sim 7 \%$ of all human malignancies. It is the eighth most common cause of cancer-related mortality worldwide, with an estimated 70,980 novel cases and 14,330 deaths annually (1). Regardless of recent advancement in multidisciplinary therapeutic strategies, bladder cancer remains associated with relapse and deterioration (2). Therefore, defining the factors involved in disease progression may aid in the identification of novel strategies for the development of effective therapies against bladder cancer.

The present study investigated exosomes, which are small membrane vesicles, 30-100 $\mathrm{nm}$ in diameter, released by a variety of mammalian cells into the extracellular space upon direct fusion of the multi-vesicular bodies with the plasma membrane (3). Exosomes contain lipids, proteins and nucleic acids from their cell of origin, contents of which are transferred to target cells and affect their function and activity (4). Thus, exosomes may be involved in cell-to-cell signaling. Several pioneering studies have investigated the involvement of exosomes in reticulocyte maturation and immune cell functions (5-6). Recently, it has been suggested that exosomes are also involved in a number of physiological and pathological processes, including cancer (7). Numerous tumor cells produce exosomes, which are emerging as a potential utility for the early detection or control of human cancer (8-11). Previous studies have demonstrated that exosomes derived from tumor cells possess anti-tumor properties, such as inducing tumor cell apoptosis (12) and enhancing anti-tumor immunity (13). Exosomes have also been extensively studied as a novel cell-free source of tumor antigens to develop anti-cancer vaccines (14-15) However, it is increasingly suggested that exosomes may also affect tumor progression by exhibiting immunosuppressive properties, facilitating tumor invasion and metastasis, stimulating tumor cell proliferation or inducing drug resistance (16) A recent study showed that gastric cancer-derived exosomes promoted tumor cell proliferation and activated the mitogen-activated protein kinase/extracellular signal-regulated kinase (MAPK/ERK) and lipid kinase phoshoinositide-3-kinase (PI3K)/Akt signaling pathways (17). 
To demonstrate the effects of bladder cancer cell-derived exosomes on the regulation of tumor cell growth and apoptosis, exosomes were isolated from bladder cancer cells and their effects in bladder cancer cell lines were investigated in vitro. It was demonstrated that bladder cancer cell-derived exosomes promoted bladder cancer cell proliferation, but inhibited apoptosis. In addition, exosomes were able to activate Akt and ERK pathways. Thus, the results of the present study provide a novel mechanism by which bladder cancer cell-derived exosomes participate in tumor progression.

\section{Materials and methods}

Cell lines and culture. T24 and 5637 human bladder cancer cell lines were provided by Professor Chun-Li Luo from the Department of Medical Diagnostics, College of Laboratory Medicine, Chongqing Medical University (Chongqing, China). Cells were cultured in RPMI-1640 (Gibco-BRL, Grand Island, NY, USA) supplemented with $10 \%$ heat-inactivated fetal bovine serum (Gibco-BRL), penicillin (100 U/ml) and streptomycin $(100 \mathrm{~g} / \mathrm{ml})$ at $37^{\circ} \mathrm{C}$ with $5 \% \mathrm{CO}_{2}$ in a humidified incubator. The cells were routinely passaged and cells at the logarithmic growth phase were used for the experiments.

Exosome isolation. The supernatants of $\mathrm{T} 24$ cells were collected and sequentially centrifuged at $4^{\circ} \mathrm{C}$ at $300 \mathrm{x}$ g for $10 \mathrm{~min}, 800 \mathrm{x} \mathrm{g}$ for $30 \mathrm{~min}$ and $10,000 \mathrm{x} \mathrm{g}$ for $30 \mathrm{~min}$ to remove cells and debris (Ultracentrifuge CP100WX; Hitachi, Tokyo, Japan). The supernatants were subjected to ultrafiltration concentration using a $100 \mathrm{kD}$ MWCO Centriplus centrifugal ultrafiltration tube (Amicon, Pineville, LA, USA) at $1,000 \mathrm{x}$ g for $30 \mathrm{~min}$. The remaining supernatants were further concentrated and subjected to ultracentrifugation on a centrifugal ultrafiltration tube containing 30\% sucrose in heavy water (Tenglong Weibo Technology, Qingdao, China) at $100,000 \mathrm{x} \mathrm{g}$ for $1 \mathrm{~h}$ at $4^{\circ} \mathrm{C}$. The sucrose solution was collected and diluted with double distilled water, followed by concentration using another $100 \mathrm{kD}$ MWCO Centriplus centrifugal ultrafiltration tube at $1,000 \mathrm{x} \mathrm{g}$ for $30 \mathrm{~min}$. The remaining exosome-containing solution was collected, filtered through a $0.22-\mu \mathrm{m}$ filter, aliquoted and stored at $-80^{\circ} \mathrm{C}$.

Transmission electron microscopy. To confirm the successful isolation of exosomes, a transmission electron microscope (JEM-2010, Jeol Ltd., Tokyo, Japan) was utilized to examine the morphology of the exosomes using a standard protocol. Briefly, a $20-\mu \mathrm{l}$ drop of exosome suspension $(\sim 100 \mu \mathrm{g} / \mathrm{ml})$ was loaded onto a copper grid to form a monolayer (staining for $1 \mathrm{~min}$ ). Excess solution was soaked out with clean filter paper. Subsequently, the sample was stained with a $20-\mu 1$ drop of $2 \%$ phosphotungstic acid (12067-99-1; Damao Chemical Reagent Factory, Tianjin, China) for $1 \mathrm{~min}$ and allowed to dry under an electric incandescent lamp (Jia Yao Lighting Co., Ltd., Foshan, China) for $10 \mathrm{~min}$. The sample was reviewed under a transmission electron microscope and images were captured (JEM-2010; Jeol, Tokyo, Japan).

Tumor cell proliferation assay. The tumor cell proliferation assay was conducted using a Cell Counting kit-8 (CCK-8; Qi-hai Biotech, Co., Shanghai, China). Briefly, 5637 and
T24 cells were seeded at 1,000 cells/well in 96-well culture plates and co-cultured with increasing concentrations of exosomes $(10,50,100,200$ and $400 \mu \mathrm{g} / \mathrm{ml})$. Cells treated with an equal volume of phosphate-buffered saline (PBS) served as controls and vials without cells were used as blank controls. Following exosome treatment for 24, 48 and $72 \mathrm{~h}$, $10 \mu \mathrm{l}$ CCK-8 solution was added to the culture medium and incubated for an additional $2 \mathrm{~h}$. Subsequent to this, the optical density of the cells was measured with a spectrophotometer (Type 752; Shanghai Yuanxi Instruments Co. Ltd., Shanghai, China) at an absorbance of $450 \mathrm{~nm}$. The cell proliferation rate was calculated using the following formula: proliferation rate $=($ experimental OD value - blank OD value $) /($ control OD value - blank OD value) $\times 100 \%$.

Annexin V apoptosis assay. To detect tumor cell apoptosis, an Annexin V-fluorescein isothiocyanate (FITC)/propidium iodide apoptosis detection kit (Invitrogen Life Technologies, Carlsbad, CA, USA) was used according to the manufacturer's instructions. Specifically, 5637 and T24 cells were seeded into six-well plates, cultured for $24 \mathrm{~h}$ and treated with various concentrations of exosomes $(10,50,100,200$ and $400 \mu \mathrm{g} / \mathrm{ml})$ at different time points $(24,48$ and $72 \mathrm{~h})$. Cells treated with an equal volume of PBS served as a control. The treated and control cells were mixed with $5 \mu \mathrm{l}$ Annexin V-FITC and $10 \mu \mathrm{l}$ of $20 \mu \mathrm{g} / \mathrm{ml}$ PI reagents. The cells were then incubated at room temperature in the dark for $20 \mathrm{~min}$. After adding $400 \mu \mathrm{l} \mathrm{PBS}$, the samples were subjected to flow cytometry analysis to detect cell apoptosis levels. Cells positive for Annexin V-FITC, but negative for PI fluorescence, were considered to represent apoptotic cells.

Reverse transcription polymerase chain reaction (RT-PCR). Total cellular RNA was isolated from treated and control tumor cells using TRIzol reagent (Invitrogen Life Technologies) according to the manufacturer's instructions. Following quantification, the RNA samples were reverse transcribed into cDNA using an RT-PCR kit (PrimeScript ${ }^{\mathrm{TM}}$ One Step RT-PCR Kit Ver.2, DRR055S; Takara, Dalian, China) according to the manufacturer's instructions. PCR amplifications were conducted at $94^{\circ} \mathrm{C}$ for $5 \mathrm{~min}, 35$ cycles at $94^{\circ} \mathrm{C}$ for $30 \mathrm{sec}, 58^{\circ} \mathrm{C}$ for $40 \mathrm{sec}$ and $72^{\circ} \mathrm{C}$ for $50 \mathrm{sec}$, with a final extension at $72^{\circ} \mathrm{C}$ for $5 \mathrm{~min}$. The primers used were as follows: Forward, 5'-GTAGCAGCGAGCAGCAGAGT-3'and reverse, 5'-CGGTCGTTGAGGAGGTTGG-3' for cyclin D1; forward, 5'-CCTAGCGGATGGGTGCTATT-3' and reverse, 5'-CGAGGTGGCAAAACAAACA-3' for caspase 3; forward, 5'-CGGCGAATTGGAGATGAA-3' and reverse, 5'-GTGTCCACGTCAGCAATCAT-3' for Bax; forward, 5'-CATGCCGTCCTTAGAAAAATACA-3' and reverse, 5'-CTGCTTTTTATTTCATGAGGTACATT-3' for Bcl-2; and forward, 5'-AGCGAGCATCCCCCAAAGTT-3' and reverse, 5'-GGGCACGAAGGCTCATCATT-3' for $\beta$-actin. The PCR products were then resolved by electrophoresis in a $1.5 \%$ agarose gel. Subsequently, the data were quantified using a gel imaging system (Vilber Lourmat, La Vallée, France).

Protein extraction and western blot analysis. Bladder cancer T24 cells treated with exosomes were lysed in a lysis buffer containing protease inhibitors for $30 \mathrm{~min}$ at $4^{\circ} \mathrm{C}$. Total cellular 
lysates were then centrifuged at $15,000 \mathrm{x}$ g for $30 \mathrm{~min}$ and the protein concentrations of the lysates were determined using the Bradford method (18). To analyze the expression of exosome proteins, $40 \mu 1$ exosome suspension was sonicated, mixed with sample buffer and boiled for $5 \mathrm{~min}$. Subsequently, equal quantities of protein samples $(10 \mu \mathrm{g})$ were separated by sodium dodecyl sulfate polyacrylamide gel electrophoresis, followed by transferring onto polyvinylidene fluoride membranes (Millipore, Bedford, MA, USA) at $250 \mathrm{~mA}$. The membranes were then blocked with $5 \%$ non-fat dry milk (w/v) in Tris-buffered saline with $0.1 \%$ Tween-20 (TBST) for $2 \mathrm{~h}$ at room temperature and immunoblotted overnight at $4^{\circ} \mathrm{C}$ using rabbit anti-human basic fibroblast growth factor (bFGF), rabbit anti-human X-linked inhibitor of apoptosis protein (XIAP), rabbit anti-human survivin (Biovision, Palo Alto, CA, USA), mouse anti-human thymidine kinase 1 (TK1; Abnova, Taipei, Taiwan), rabbit anti-human CD63, mouse anti-human Bcl-2, mouse anti-human Bax, rabbit anti-human cyclin D1, rabbit anti-human caspase-3 (Santa Cruz Biotechnology, Inc., Santa Cruz, CA, USA), rabbit anti-human Akt and phospho-Akt1/2 (Ser 473) or rabbit anti-human ERK and phospho-ERK1/2 (Cell Signaling Technology, Danvers, MA, USA) antibodies. Following three rinses with TBST at 15 min intervals, the membranes were further incubated for $1 \mathrm{~h}$ with horseradish peroxidase-labeled goat anti-rabbit or anti-mouse IgG (Zhongshan Golden Bridge, Beijing, China). The positive protein bands were detected using an enhanced chemiluminescence (ECL) plus chemiluminescence kit (P0018; Beyotime Institute of Biotechnology, Haimen, China).

Statistical analysis. Each experiment was repeated at least three times. All data are presented as the mean \pm SD. Student's t-test was used to compare the differences between two groups. All statistical analyses were performed using SPSS 17.0 software (SPSS Inc., Chicago, IL, USA). P $<0.05$ was considered to indicate a statistically significant difference.

\section{Results}

Isolation and characterization of bladder cancer T24 cell-derived exosomes. In the present study, exosomes were purified from T24 cells by sequential centrifugation and ultrafiltration, and their identity was confirmed under a transmission electron microscope. The data showed that these exosomes were round-shaped vesicular membrane structures, 30-100 $\mathrm{nm}$ in diameter (Fig. 1). In addition, western blot analysis demonstrated that XIAP, survivin, bFGF, TK1 and CD63 were abundant in these isolated exosomes compared with the whole-cell lysates of T24 cells (Fig. 2).

Bladder cancer cell-derived exosomes promote tumor cell viability. To determine the effects of T24 cell-derived exosomes on the regulation of renal clear cell carcinoma cell proliferation, the viability of 5637 and T24 cells was analyzed following treatment with various concentrations of exosomes $(10,50,100,200$ and $400 \mu \mathrm{g} / \mathrm{ml})$ for up to $72 \mathrm{~h}$. The results of the cell viability CCK-8 assay showed that these exosomes significantly induced the viability of 5637 and T24 cells in a time- and dose-dependent manner (Fig. 3). A maximal increase in tumor cell proliferation was achieved following

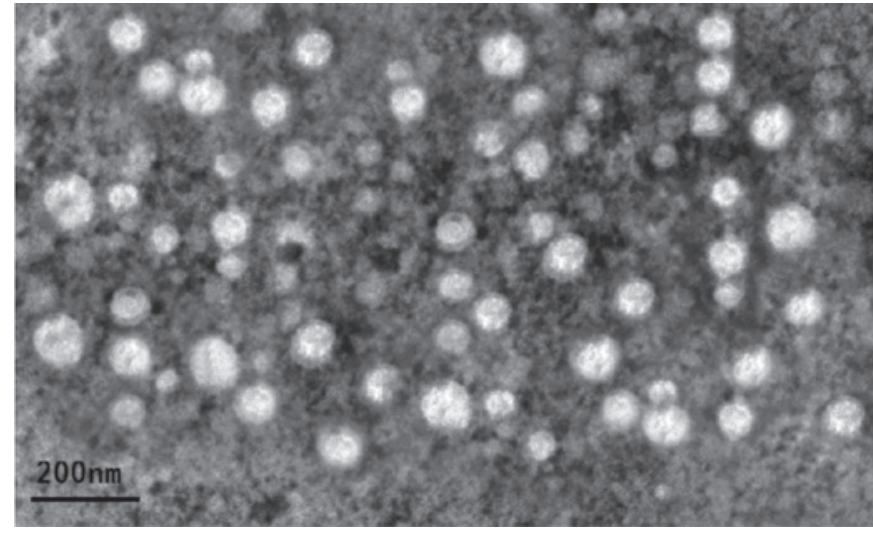

Figure 1. Identification of bladder cancer cell-derived exosomes. The exosomes were isolated and purified from T24 cells and observed under a transmission electron microscope. Cells exhibited a characteristic saucer-like shape, with a diameter of 30-100 nm. Original magnification, x 50,000.

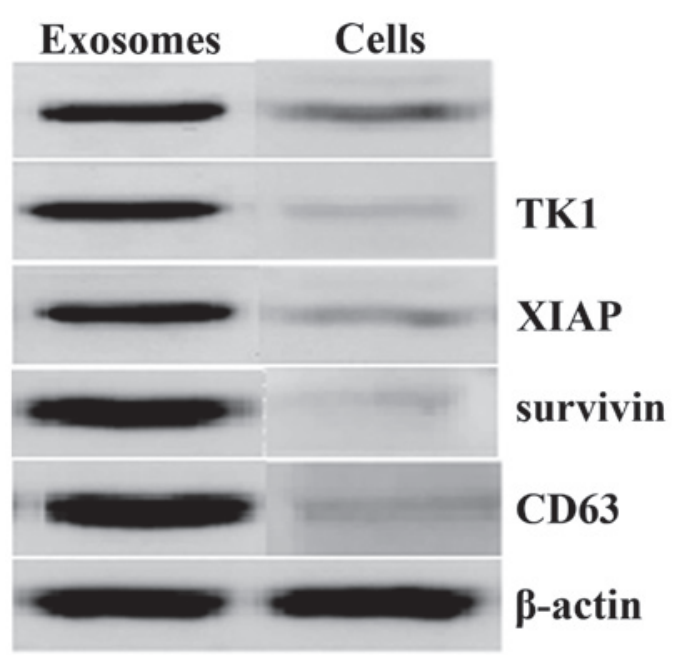

Figure 2. Western blot analysis of protein expression in T24 cell-derived exosomes and whole-cell lysates of T24 cells. X-linked inhibitor of apoptosis protein (XIAP), survivin, basic fibroblast growth factor (bFGF), thymidine kinase 1 (TK1), and CD63 proteins had an increased expression in exosomes compared with the whole-cell lysates.

treatment with $400 \mu \mathrm{g} / \mathrm{ml}$ exosomes for $72 \mathrm{~h}$, and the viabilities of 5637 and T24 cells were increased by $76.52 \%$ and $73.26 \%$, respectively.

Bladder cancer cell-derived exosomes inhibit tumor cell apoptosis. To investigate the potential cause of the induced tumor cell viability by the exosomes, an Annexin V/flow cytometric apoptosis assay was performed following the treatment of 5637 and T24 cells with increasing concentrations of exosomes $(10,50,100,200$ and $400 \mu \mathrm{g} / \mathrm{ml})$ for up to $72 \mathrm{~h}$. It was demonstrated that these exosomes dose- and time-dependently inhibited the apoptosis of 5637 and T24 cells, with the maximal reduction occurring following treatment with $400 \mu \mathrm{g} / \mathrm{ml}$ exosomes for $72 \mathrm{~h}$ (Table I, Fig. 4). Moreover, the expression of apoptosis-related genes was analyzed in these cells. As shown in Fig. 5, the levels of Bcl-2 mRNA and protein were increased following 100 and $400 \mu \mathrm{g} / \mathrm{ml}$ exosome treatment for $72 \mathrm{~h}$, whereas the levels of Bax mRNA and protein were markedly reduced in these cells. In addition, downregulation of caspase-3 
Table I. Effect of bladder cancer cell-derived exosomes on induction of bladder cancer cell apoptosis.

A. Rate of 5637 cell apoptosis following exosome treatment.

Apoptosis rate $(\%)$ at time interval

Exosome concentration $(\mu \mathrm{g} / \mathrm{ml})$

\begin{tabular}{ccc}
\hline $24 \mathrm{~h}$ & $48 \mathrm{~h}$ & $72 \mathrm{~h}$ \\
$4.46 \pm 0.27$ & $4.42 \pm 0.16$ & $4.59 \pm 0.18$ \\
$3.82 \pm 0.10^{\mathrm{a}}$ & $3.64 \pm 0.12^{\mathrm{a}}$ & $3.54 \pm 0.23^{\mathrm{a}}$ \\
$2.86 \pm 0.05^{\mathrm{b}}$ & $2.33 \pm 0.07^{\mathrm{b}}$ & $2.19 \pm 0.08^{\mathrm{b}}$ \\
$2.04 \pm 0.07^{\mathrm{b}}$ & $1.93 \pm 0.11^{\mathrm{b}}$ & $1.84 \pm 0.05^{\mathrm{b}}$ \\
$1.36 \pm 0.05^{\mathrm{b}}$ & $1.32 \pm 0.04^{\mathrm{b}}$ & $1.23 \pm 0.04^{\mathrm{b}}$ \\
$0.95 \pm 0.05^{\mathrm{b}}$ & $0.66 \pm 0.08^{\mathrm{b}}$ & $0.36 \pm 0.03^{\mathrm{b}}$ \\
\hline
\end{tabular}

B. Rate of T24 cell apoptosis following exosome treatment.

\begin{tabular}{rccc}
\hline & \multicolumn{3}{c}{ Apoptosis rate $(\%)$ at time interval } \\
\cline { 2 - 4 } Exosome concentration $(\mu \mathrm{g} / \mathrm{ml})$ & $24 \mathrm{~h}$ & $48 \mathrm{~h}$ & $4.47 \pm 0.15$ \\
\hline 0 & $4.43 \pm 0.26$ & $4.35 \pm 0.31$ & $3.57 \pm 0.20^{\mathrm{a}}$ \\
10 & $3.74 \pm 0.12^{\mathrm{a}}$ & $3.63 \pm 0.12^{\mathrm{a}}$ & $2.18 \pm 0.10^{\mathrm{b}}$ \\
50 & $2.77 \pm 0.17^{\mathrm{b}}$ & $2.34 \pm 0.10^{\mathrm{b}}$ & $1.84 \pm 0.06^{\mathrm{b}}$ \\
100 & $2.01 \pm 0.09^{\mathrm{b}}$ & $1.95 \pm 0.11^{\mathrm{b}}$ & $1.26 \pm 0.07^{\mathrm{b}}$ \\
200 & $1.37 \pm 0.04^{\mathrm{b}}$ & $1.32 \pm 0.08^{\mathrm{b}}$ & $0.33 \pm 0.04^{\mathrm{b}}$ \\
400 & $0.92 \pm 0.06^{\mathrm{b}}$ & $0.63 \pm 0.06^{\mathrm{b}}$ & \\
\hline
\end{tabular}

${ }^{\mathrm{a}} \mathrm{P}<0.05$ and ${ }^{\mathrm{b}} \mathrm{P}<0.01$, compared with the control.
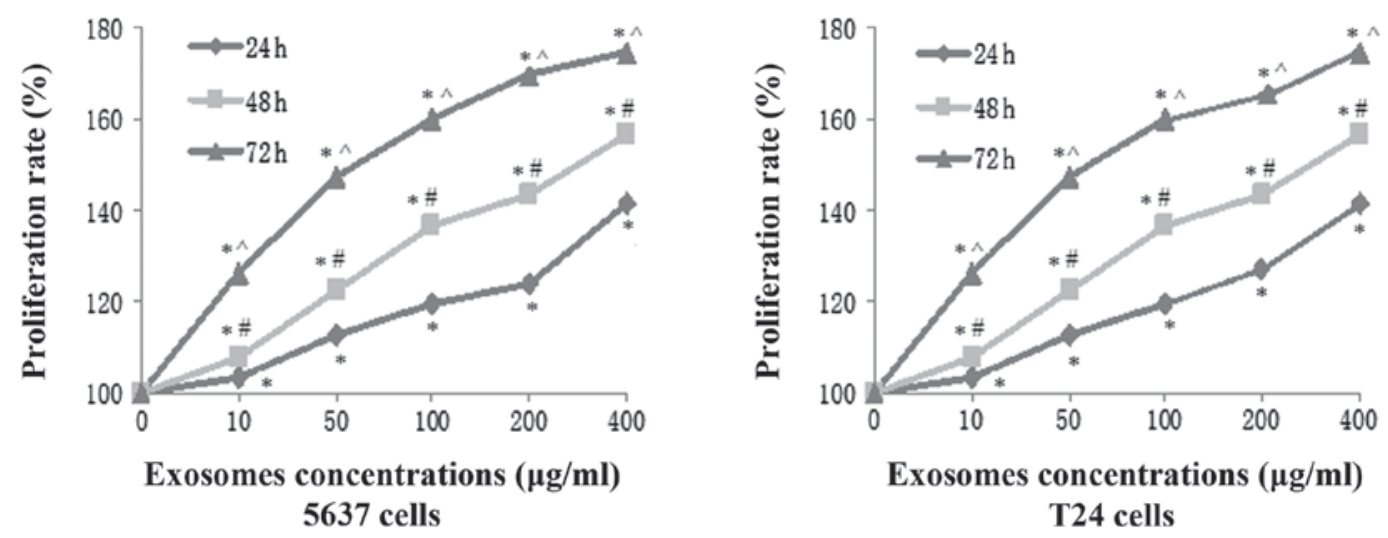

Figure 3. Effect of bladder cancer cell-derived exosomes on regulating the proliferation of 5637 and T24 cells. 5637 and T24 cells were treated with various concentrations of exosomes $(10,50,100,200$ and $400 \mu \mathrm{g} / \mathrm{ml})$ for 24,48 and $72 \mathrm{~h}$. Cell viability was assessed by a Cell Counting kit- 8 assay. "P $<0.05$ vs. the untreated cells; ${ }^{\sharp} \mathrm{P}<0.05$ vs. the cells treated with exosomes for $24 \mathrm{~h}$ and ${ }^{\wedge} \mathrm{P}<0.05$ vs. the cells treated with exosomes for $48 \mathrm{~h}$.

protein, an executioner of apoptosis, was observed. However, the levels of caspase-3 mRNA were not significantly changed in T2 4 cells following treatment with 100 or $400 \mu \mathrm{g} / \mathrm{ml}$ exosomes for $72 \mathrm{~h}$. In addition, the expression of cyclin D1 protein was significantly increased in T24 cells following treatment with 100 and $400 \mu \mathrm{g} / \mathrm{ml}$ exosomes for $72 \mathrm{~h}$.

Bladder cancer cell-derived exosomes activate Akt and ERK in bladder cancer cells. To demonstrate the mechanism underlying these phenotypic changes in bladder cancer cells following exosome treatment, the activity of Akt and ERK1/2 proteins in T24 cells was analyzed following treatment with 100 and $400 \mu \mathrm{g} / \mathrm{ml}$ exosomes for $72 \mathrm{~h}$. Data showed that exosome treatment dose-dependently upregulated the expression of phosphorylated Akt and ERK1/2 compared with that of the untreated control cells (Fig. 5B), suggesting that the activation of the Akt and ERK pathways may participate in the exosome-stimulated proliferation of bladder carcinoma cells. 


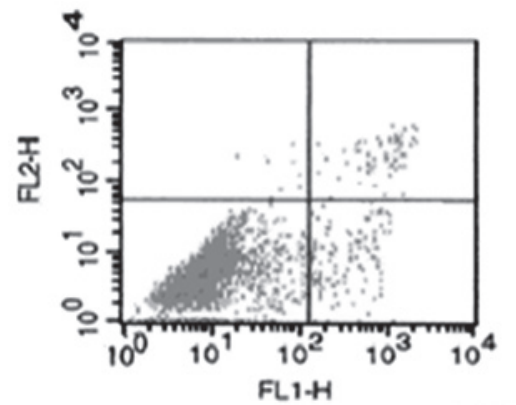

$\mathbf{5 6 3 7}$ cells apoptosis rates: $4.59 \%$

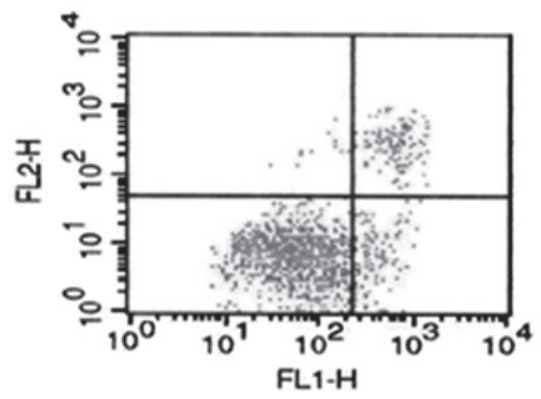

T24 cells apoptosis rates: $4.47 \%$
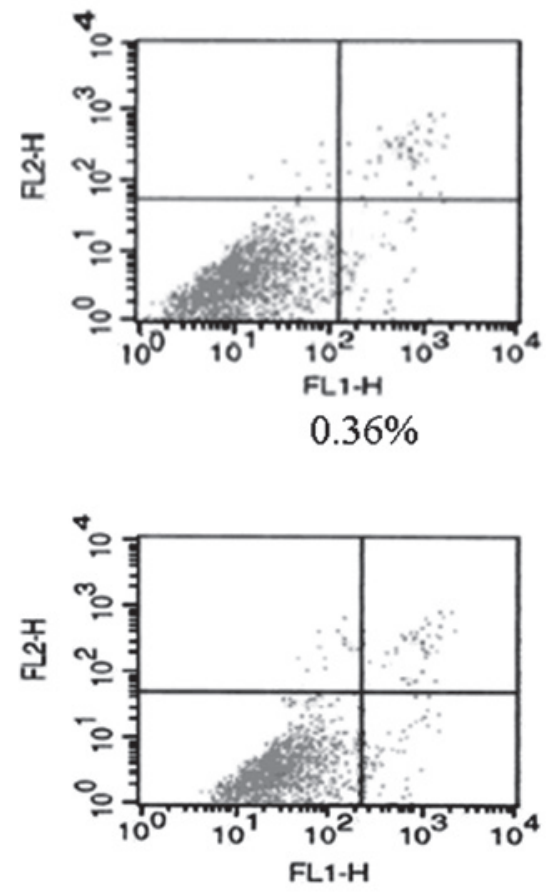

$0.33 \%$

Figure 4. Effect of bladder cancer cell-derived exosomes on regulating apoptosis in 5637 and T24 cells. Apoptosis was determined by the Annexin V/flow cytometric apoptosis assay. Compared with the control, the apoptosis rates of 5637 and T24 cells following treatment with $400 \mu \mathrm{g} / \mathrm{ml}$ exosomes for $72 \mathrm{~h}$ were $0.36 \%$ and $0.33 \%$, respectively. FL1-H or FL1-Height, channel 1, represents Annexin V-fluorescein isothiocyanate fluorescence, while FL2-H or FL2-Height, channel 2, represents propidium iodide fluorescence.

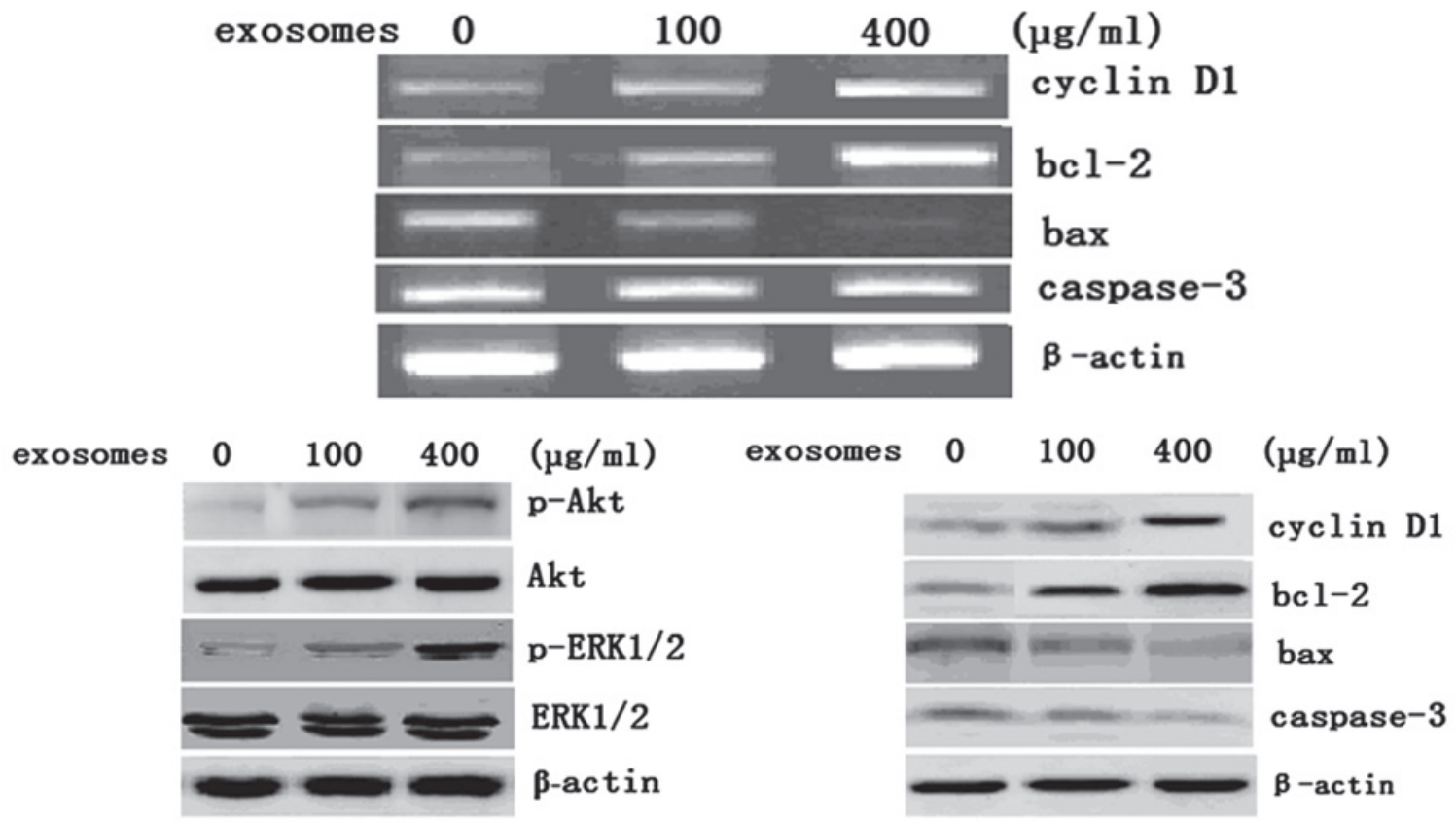

Figure 5. Effects of bladder cancer cell-derived exosomes on the differentially regulating expression of Bax, Bcl-2, caspase-3 and cyclin D1 mRNA and proteins, and phosphorylated (p)-Akt and p-extracellular signal-regulated kinase (ERK)1/2 proteins in T24 cells. (A) RT-PCR analysis of Bax, Bcl-2, caspase-3 and cyclin D1 mRNA levels in T24 cells treated with 100 and $400 \mu \mathrm{g} / \mathrm{ml}$ exosomes for $72 \mathrm{~h}$. (B) Western blot analysis of Bax, Bcl-2, caspase-3, cyclin D1 and p-Akt and ERK1/2 expression in T24 cells following treatment with 100 and $400 \mu \mathrm{g} / \mathrm{ml}$ exosomes for $72 \mathrm{~h}$. RT-PCR, reverse transcription PCR.

\section{Discussion}

In the present study, bladder cancer cell-derived exosomes were isolated and identified, and it was demonstrated that these exosomes induced the viability of bladder cancer cells and suppressed tumor cell apoptosis. It was also observed that exosome treatment upregulated Bcl-2 and cyclin-D1 expression, but decreased Bax and caspase-3 protein levels, 
which was correlated with the inhibition of apoptosis in these tumor cell lines. Exosome treatment also promoted the phosphorylation of Akt and ERK proteins. However, the underlying mechanisms responsible for exosome release from tumor cells and their involvement in vivo requires further investigation. Inhibition of exosome formation and their release from tumor cells may be a novel strategy for effectively controlling human cancer.

Exosomes, which are secreted by various mammalian cells, merge with and release their contents into cells that are distant from their cell of origin, or in our case, the same origin of the tumor cells. In addition, exosomes influence the behavior and activity of the recipient cells, including cell growth, differentiation and apoptosis. Exosomes are also considered to be vital in tumor progression (19). However, it remains unknown why and how exosomes form and are secreted from host cells and which types of biological processes they participate in within the target cells. The mechanism underlying the contribution of tumor-released exosomes to tumorigenesis remains to be fully elucidated (16).

In the present study, exosomes were successfully isolated and purified from the supernatants of T24 human bladder cancer cells using a commercially available exosome purification kit. These exosomes were identified to be similar to those from other sources $(15,20-22)$ and were rich in certain hallmark proteins, such as CD63. In addition, the isolated exosomes contained concentrated levels of different proteins, including XIAP, survivin, bFGF and TK1, which are important in cell growth, apoptosis and angiogenesis. Subsequent to merging with recipient cells, exosomes most likely promote the growth of recipient cells, as well as inhibit apoptosis.

Moreover, the current study determined the effects of bladder cancer cell-derived exosomes on the regulation of bladder cancer cell viability and apoptosis in vitro. It was identified that these exosomes induced the viability of 5637 and T24 cells in a time- and dose-dependent manner. These results are consistent with those of previous studies showing that breast and gastric cancer cell-released exosomes stimulated the proliferation of their parental cells in vitro $(17,23)$. In addition, these results suggest that certain common molecular events or mechanisms may be responsible for tumor-derived exosomes in the promotion of cell proliferation and the suppression of apoptosis. Thus, tumor-derived exosomes may exhibit crucial growth-promoting effects that are involved in cancer progression. Furthermore, the upregulation of $\mathrm{Bcl}-2$ and downregulation of Bax and caspase- 3 in exosome-treated bladder cancer cell lines was also observed. A previous study showed that a variety of cancer cells were able to take up survivin, an anti-apoptotic protein, from extracellular media, thereby inhibiting apoptosis and increasing metastatic capability (24). These data may provide molecular insight into the involvement of exosomes in cell-to-cell signaling. Further studies are required to investigate molecular signaling in the formation and release of exosomes from the host cells and their affect on the recipient cells.

The PI3K/Akt and MAPK/ERK pathways are prototypic survival signaling pathways and are critical in mediating survival signals in a wide range of cell types. A previous study demonstrated that gastric cancer-derived exosomes promoted tumor cell proliferation through the activation of MAPK/ERK and PI3K/Akt signaling pathways (17). Thus, the present study was shown to be concurrent with this data by demonstrating that bladder cancer cell-derived exosomes dose-dependently increased the expression of phosphorylated Akt and ERK1/2. However, in these cell lines, it remains to be determined how signaling transduction of these genes results in the upregulation of Bcl-2 and cyclin D1 and downregulation of Bax and caspase-3.

Tumor cell-derived exosomes may exert diverse biological functions leading to tumor progression and metastasis. Future studies are required to investigate the potential of exosomes to effectively deliver therapeutic drugs for cancer therapy.

\section{References}

1. Jemal A, Siegel R, Ward E, Hao Y, Xu J and Thun MJ: Cancer statistics, 2009. CA Cancer J Clin 59: 225-249, 2009.

2. Hurst R: Does the biomarker search paradigm need re-booting? BMC Urol 9: 1, 2009.

3. Vlassov AV, Magdaleno S, Setterquist R and Conrad R: Exosomes: Current knowledge of their composition, biological functions, and diagnostic and therapeutic potentials. Biochim Biophys Acta 1820: 940-948, 2012.

4. Mathivanan S, Ji H and Simpson RJ: Exosomes: extracellular organelles important in intercellular communication. J Proteomics 73: 1907-1920, 2010.

5. Johnstone RM, Adam M, Hammond JR, et al: Vesicle formation during reticulocyte maturation. Association of plasma membrane activities with released vesicles (exosomes). J Biol Chem 262: 9412-9420, 1987.

6. Potolicchio I,Carven GJ, Xu X, et al: Analysis of microglia-derived exosomes: metabolic role of the aminopeptidase CD13 in neuropeptide catabolism. J Immunol 175: 2237-2243, 2005.

7. Henderson MC and Azorsa DO: The genomic and proteomic content of cancer cell-derived exosomes. Front Oncol 2: 38, 2012.

8. Taylor DD and Gercel-Taylor C: MicroRNA signatures of tumor-derived exosomes as diagnostic biomarkers of ovarian cancer. Gynecol Oncol 110: 13-21, 2008.

9. Rosell R, Wei J and Taron M: Circulating microRNA signatures of tumor-derived exosomes for early diagnosis of non-small-cell lung cancer. Clin Lung Cancer 10: 8-9, 2009.

10. Rabinowits G, Gerçel-Taylor C, Day JM, Taylor DD and Kloecker GH: Exosomal microRNA: a diagnostic marker for lung cancer. Clin Lung Cancer 10: 42-46, 2009.

11. Simpson RJ, Lim JW, Moritz RL and Mathivanan S: Exosomes: proteomic insights and diagnostic potential. Expert Rev Proteomics 6: 267-283, 2009.

12. Ristorcelli E, Beraud E, Verrando P, Villard C, Lafitte D, Sbarra V, et al: Human tumor nanoparticles induce apoptosis of pancreatic cancer cells. FASEB J 22: 3358-3369, 2008.

13. Zhang Y, Luo CL, He BC, Zhang JM, Cheng G and Wu XH: Exosomes derived from IL-12-anchored renal cancer cells increase induction of specific antitumor response in vitro: a novel vaccine for renal cell carcinoma. Int J Oncol 36: 133-140, 2010.

14. Wolfers J, Lozier A, Raposo G, Regnault A, Théry C, Masurier C, et al: Tumor-derived exosomes are a source of shared tumor rejection antigens for CTL cross-priming. Nat Med 7: 297-303, 2001.

15. Andre F, Schartz NE, Movassagh M, Flament C, Pautier P, Morice $\mathrm{P}$, et al: Malignant effusions and immunogenic tumour-derived exosomes. Lancet 360: 295-305, 2002.

16. Yang $\mathrm{C}$ and Robbins PD: The roles of tumor-derived exosomes in cancer pathogenesis. Clin Dev Immunol 2011: 842849, 2011.

17. Qu JL, Qu XJ, Zhao MF, Teng YE, Zhang Y, Hou KZ, et al: Gastric cancer exosomes promote tumour cell proliferation through PI3K/Akt and MAPK/ERK activation. Dig Liver Dis 41: 875-880, 2009.

18. Bradford MM: A rapid and sensitive method for the quantitation of microgram quantities of protein utilizing the principle of protein-dye binding. Anal Biochem 72: 248-254, 1976.

19. Camussi G, Deregibus MC, Bruno S, Grange C, Fonsato V and Tetta C. Exosome/microvesicle-mediated epigenetic reprogramming of cells. Am J Cancer Res 1: 98-110, 2011. 
20. Raposo G, Nijman HW, Stoorvogel W, Liejendekker R, Harding CV, Melief CJ and Geuze HJ: B lymphocytes secrete antigen-presenting vesicles. J Exp Med 183: 1161-1172, 1996.

21. Théry C, Regnault A, Garin J, Wolfers J, Zitvogel L, Ricciardi-Castagnoli P, et al: Molecular characterization of dendritic cell-derived exosomes. Selective accumulation of the heat shock protein hsc73. J Cell Biol 147: 599-610, 1999.

22. Lamparski HG, Metha-Damani A, Yao JY, Patel S, Hsu DH, Ruegg C and Le Pecq JB: Production and characterization of clinical grade exosomes derived from dendritic cells. J Immunol Methods 270: 211-226, 2002
23. Koga K, Matsumoto K, Akiyoshi T, Kubo M, Yamanaka N, Tasaki A, et al: Purification, characterization and biological significance of tumor-derived exosomes. Anticancer Res 25: 3703-3707, 2005

24. Khan S, Aspe JR, Asumen MG, Almaguel F, Odumosu O, Acevedo-Martinez S, et al: Extracellular, cell-permeable survivin inhibits apoptosis while promoting proliferative and metastatic potential. Br J Cancer 100: 1073-1086, 2009. 